\title{
Influência do alimento na produção e qualidade do leite de cabra
}

\author{
Roberto Germano Costa ${ }^{1}$, Rita de Cássia R. E. Queiroga ${ }^{1}$, Renata A. G. Pereira ${ }^{1}$ \\ ${ }^{1}$ Programa de Doutorado Integrado em Zootecnia. Universidade Federal da Paraíba (UFPB).
}

RESUMO - O leite de cabra é considerado um dos alimentos mais completos por apresentar vários elementos importantes para a nutrição humana, constituído de proteínas de alto valor biológico e ácidos graxos essenciais, além de seu conteúdo mineral e vitamínico. Esta revisão tem como objetivo avaliar as variações referentes à composição química e propriedades físicoquímicas do leite, que ocorrem em função de alguns fatores, tais como: climáticos, raça, indivíduo, estágio de lactação e alimentação. O manejo alimentar tem sido considerado um fator preponderante na manipulação dos componentes do leite. Há um entendimento dominante que a gordura é o componente do leite que mais sofre influência dos alimentos. O uso de técnicas biológicas moleculares poderá contribuir para o entendimento do mecanismo de utilização do alimento no rúmen, estabelecendo um novo cenário para a microbiologia ruminal, que pode ser diferente do que tem sido estudado até o momento.

Palavras-chave: alimentação, caprinos, composição química, nutrição, perfil lipídico

\section{Influence of feed on the production on quality of goat milk}

\begin{abstract}
Goat milk is considered one of the most complete foods, since it holds several elements which are important for human nutrition, and necessary for the constitution of tissues and blood. This revision aims to assess the variations of the chemical composition and physical-chemical properties of the milk which occur due to some factors, such as: climate, breed, the individual, lactation stage and food. Feed management has been considered a key factor in the manipulation of milk components. There is a general understanding that among the components of the milk fat is the most influenced by food. The use of molecular biological techniques might contribute to the understanding of the mechanism of utilization of food in rumen, establishing a new possibility for ruminal microbiology, which can be different from what has been studied so far.
\end{abstract}

Key Words: feed, goats, chemical composition, nutrition, lipid profile

\section{Introdução}

Em torno de $74 \%$ do rebanho mundial de caprinos encontram-se difundidos nas regiões tropicais e áridas. No Brasil, cerca de $90 \%$ do rebanho caprino encontra-se na região Nordeste, principalmente na zona semi-árida. Constitui-se em uma espécie de expressiva importância econômica graças a sua rusticidade, que permite uma melhor adaptação às características do meio, ressaltando-se a qualidade dos produtos que fornece para a alimentação e vestuário (Dubeuf et al., 2004).

A demanda por produtos de origem animal de qualidade torna-se cada vez mais visada pelo mercado consumidor gerando a busca pela produção e processamento de alimentos cada vez mais elaborados e com certificação de qualidade garantida. Tal fato não é diferente para o leite caprino, o qual necessita da aplicação de métodos de produção e beneficiamento diferenciados para que sejam oferecidos produtos melhorados (Raynal-Ljutovac et al.,
2008), desmistificando o leite de cabra como alimento pouco palatável, levando a sua expansão em âmbito nacional.

A população de pequenos ruminantes é vista como uma fonte sustentável com excelente possibilidade de rentabilidade econômica e estabilidade demográfica, o que a torna de especial importância para as regiões áridas e semi-áridas. As raças nativas são exploradas nessas regiões em regimes extensivos ou semi-extensivos, porém são animais valiosos devido a sua variabilidade genética e por possuírem custos de produção mais baixos devido ao uso apropriado dos recursos naturais (Sanz Sampelayo et al., 2007).

O fato de o leite caprino apresentar uma composição química constituída de proteínas de alto valor biológico e ácidos graxos essenciais, além de seu conteúdo mineral e vitamínico, o qualifica como um alimento de elevado valor nutricional, ainda representando grande importância na alimentação infantil pelas suas características de hipoalergenicidade e digestibilidade devido aos glóbulos 
de gordura diminuídos (Haenlein, 2004). A gordura do leite é o componente do leite que mais sofre influência da alimentação. Essas alterações não ocorrem somente com relação à sua concentração, mas também na composição dos ácidos graxos (Lucas et al., 2008). No âmbito da pesquisa, a composição do leite caprino vem sendo estudada em diversas partes do mundo com intuito de obter qualidade e aceitação do produto, assim como acentuar substâncias benéficas a saúde humana. Entretanto, existem lacunas de informações sobre a composição química em regiões tropicais e em suas microrregiões, sobretudo a influência de múltiplos fatores, como raça, mestiçagem, ambiente, alimentação e período de lactação sobre a qualidade do leite produzido.

Neste contexto, informações a respeito da produção e qualidade nutricional do leite caprino, relacionando os principais fatores que afetam este parâmetro, enfatizandose os dados nacionais com as raças nativas, apresentam-se como contribuição na busca de alternativas para a caprinocultura leiteira nacional e o fortalecimento desta cadeia produtiva

\section{Fatores que influenciam a qualidade do leite}

Os fatores que afetam as características químicas, físicas e as propriedades do leite caprino podem ser genéticos, fisiológicos, climáticos e principalmente de origem alimentar.

\section{Genéticos}

Ferreira \& Queiroga (2003) trabalhando com três genótipos (Anglo Nubiano, Parda Alemã e British Alpine) encontraram que valores médios de proteínas, lipídios, extrato seco total, cinzas e ácido láctico, sofreram influência significativa da raça, o que não aconteceu com os teores de lactose, tendo a raça Anglo Nubiana como a que apresentaram os maiores valores.

Estudos comparativos das características do leite de cabra contendo altos e baixos níveis deáS1-caseína(Jaubert, 1997) mostraram que o genótipo tem um efeito significativo no conteúdo de caseína, percentagem de gordura e características de micela (tamanho e mineralização).

Os glóbulos de gordura do leite de cabra se apresentam menores, o que pode explicar a sua maior digestibilidade, Isso porque cerca de $20 \%$ dos ácidos graxos na gordura do leite de cabra são de cadeia curta (C4:0 - C12:0), mais facilmente digeridos. Há diferenças quanto ao teor de gordura entre o leite de cabra e vaca, tanto do ponto de vista quantitativo quanto do ponto de vista físico, sendo relatados valores entre 2,0 a $8,0 \%$ de gordura para o leite de cabra (Jenness, 1980).
Diferenças na produção e composição do leite também foram verificadas por Prasad et al. (2005), quando trabalharam com 32 cabras puras Beetal, 16 Beetal x Jamunapari, 31 Beetal x Barbari, 19 Beetal x Black Bengal, todas na fase intermediária de lactação e mantidas sob mesmo manejo. Nesse estudo, foi demonstrado que fatores genéticos alteraram a produção e a composição química do leite.

\section{Fisiológicos}

O período de lactação assim como a raça representa, também, um fator de variação nas características da composição do leite caprino. Quanto mais o animal avança no seu período de lactação, mais haverá uma tendência de diminuição na quantidade de leite produzido, conseqüentemente no teor de lactose, com possível aumento em dois outros constituintes: gordura e proteína.

Ferreira \& Queiroga (2003) trabalhando com três genótipos (Anglo Nubiano, Parda Alemã e British Alpine), observaram que os valores médios de proteínas, lipídios, extrato seco total, cinzas e ácido láctico sofreram influência significativa do período de lactação e do turno de ordenha, porém, esta mesma influência não foi verificada para os teores de lactose.

Um estudo analisando perfil de ácidos graxos do leite de cabra em função da fase de lactação observou variações, apresentando os maiores percentuais de ácidos graxos de cadeia curta na fase intermediária como também, os teores médios de ácidos graxos insaturados foram modificados por este fator, notando-se valores superiores na fase inicial da lactação (Queiroga et al., 2007).

Brito et al. (2004), estudando cabras da raça Murciana Granadina (puro de origem, puro por cruza e mestiço) num período de 181 dias de lactação verificaram uma maior produção para o grupo mestiço $(658,5 \mathrm{~g} / \mathrm{dia})$ e constatou uma queda $(\mathrm{P}<0,05)$ da produção de leite de acordo com o período de lactação, demonstrando uma maior persistência de lactação dos animais mestiços.

Estudos demonstram que o número de lactações é outro fator fisiológico que também interfere na produção e composição do leite. Prasad et al. (2005), trabalhando com animais da raça Beetal cruzados com diferentes raças, onde todos se encontravam na fase intermediária de lactação e mantidos no mesmo manejo não encontraram diferenças $(\mathrm{P}>0,05)$ para os teores de gordura entre animais de primeira ou mais crias. No entanto, para os teores de proteína, lactose e sólidos totais houve uma diminuição $(\mathrm{P}<0,05)$ destes valores com o aumento no número de parições.

Adaver et al. (2009), estudando cabras Malagenhas com diferentes genótipos e diferentes níveis de proteína, observaram variações no perfil lipídico com produção de 
maior teor de ácidos graxos de cadeia e média, quando utilizado níveis elevados de proteína na dieta, bem como, forte interação do genótipo, nível de proteína na dieta com a capacidade de produção de áS ${ }_{1}$-caseína.

\section{Climáticos}

Do ponto de vista bioclimatológico, apesar de os caprinos serem considerados animais rústicos, a associação de elevadas temperaturas e altas umidades do ar e radiação, o que caracteriza um estresse térmico, pode acarretar alterações comportamentais e fisiológicas, como redução no consumo de MS e aumento na ingestão de água.

Brasil et al. (2000), trabalhando com cabras da raça Parda Alpina, na $5^{\text {a }}$ semana de lactação obtiveram produção média de 2,5 kg/dia, divididas em dois grupos. Um sob estresse térmico, mantidos em câmara climática por 56 dias de radiação e o outro em condições de termoneutralidade. Os animais estressados reduziram a ingestão de alimentos e duplicaram o consumo de água, diminuindo com isso a produção de leite, a porcentagem de gordura, de proteína, de lactose e de sólidos totais.

\section{Alimentação}

A alimentação tem sido um fator preponderante na manipulação dos componentes do leite. Há um entendimento dominante que a gordura é o componente do leite que mais sofre influência da alimentação. Essas alterações não ocorrem somente com relação a sua concentração, mas também com a composição dos ácidos graxos. O comprimento da cadeia carbônica (cadeia curta ou longa), grau de saturação (saturado ou poli-insaturado) e isomeria geométrica (cis ou trans) dos ácidos graxos exercem mudanças nas propriedades tecnológicas da gordura como a textura e oflavour da manteiga e queijo, em razão dos diferentes pontos de fusão desses componentes (Coulon \& Priolo, 2002).

A formulação de dietas para a produção de leite a partir de novos sistemas que incorporam modelos mais complexos para a estimativa da degradação dos nutrientes do rúmen, bem como das estimativas da síntese de proteínas, proporcionam uma maior eficiência na utilização dos nutrientes (Hoover \& Stokes, 1991).

Goetsch et al. (2001), estudando o efeito da dieta na produção e composição do leite de cabras Alpinas, observaram que o fator dieta tem efeito sobre os teores de gordura do leite, verificando relação direta com a ingestão e com o metabolismo energético.

Os principais fatores que modificam a composição da gordura são: a natureza da fonte lipídica e a fonte de fibras das dietas (Morand-Fehr et al., 2000). Desde a década de
1930, sabe-se que o teor de gordura diminui na medida em que o teor de concentrados se eleva na dieta. A hipótese tradicionalmente empregada para explicar a relação entre excesso de concentrado e baixa gordura centraliza-se na alteração da proporção de ácidos graxos produzidos no rúmen. O aumento no fornecimento de concentrado eleva a produção do ácido propiônico e lático acarretando na redução do $\mathrm{pH}$ ruminal.

Sob pH ruminal menor que 6,0, a degradação da fibra é bastante prejudicada, diminuindo a produção de ácido acético em contraposição ao ácido propiônico, que aumenta. Sendo o ácido acético o principal precursor da gordura do leite, a sua redução estaria então diretamente relacionada à queda na produção de gordura (Nocek, 1997).

Modificações no nível, tipo de forragem e forma física pode alterar a composição de ácidos graxos e estes podem afetar a textura dos produtos processados. As proteínas, em particular as caseínas têm grande importância na tecnologia de leite, principalmente na fabricação de queijos, e, portanto, fatores alimentares que possam aumentar a sua concentração no leite vêm sendo estudados. Segundo Carvalho et al. (2001), a redução do desempenho animal devido à menor quantidade $\mathrm{d}$ e fibra na dieta é descrita através de uma série de eventos que se iniciam pela redução da atividade mastigatória, o que leva à menor secreção de saliva, o que favorece a redução do $\mathrm{pH}$ ruminal, alteração do padrão de fermentação, redução da relação acetato:propionato, que em última análise, altera o metabolismo animal, com redução do te or de gordura do leite.

Cabras alimentadas com níveis altos de forragens produziram conteúdos mais elevados dos ácidos graxos C4:0, C6:0, C18:0, C18:1, C18:3 e C20:0 (Le Doux et al, 2002). Todavia, níveis elevados de alfafa produzem valores mais baixos detrans-C18:1. Assim, diminuindo-se o conteúdo de fibras e aumentando-se grãos na ração diária dos animais, produzem-se teores mais altos deste ácido graxo no leite.

Torii et al. (2004) avaliaram as características físicoquímicas e o perfil de ácidos graxos do leite de cabras Saanen em resposta a diferentes fontes de volumoso (feno de alfafa, feno de aveia, e silagem de milho). Os resultados indicaram que a fonte de volumoso em dietas de cabras em lactação afeta a composição em ácidos graxos sem alterar as características físico-químicas do leite.

Sanz Sampelayo et al. (2002) estudando a inclusão de 9 e $12 \%$ na MS de gordura protegidas rica em PUFAs na dieta de cabras observou que o teor total de proteína e a proporção de caseína não foi modificado, no entanto houve um decréscimo no teor de $\alpha$-caseína, importante proteína na tecnologia de leite, devido a suas propriedades coagulantes. 
Coulon et al. (1998) avaliando diferentes fatores alimentares (nível e natureza das dietas energéticas e azotadas) em vacas na relação caseína/proteína do leite não verificou efeito significativo, salvo em condições de subalimentação acentuada. Nesta mesma pesquisa, quando se avaliou o efeito da natureza e modo de conservação das forragens (in natura, feno e silagem) observou-se que a composição química do leite foi fortemente modificada, mas não a relação caseína/proteína.

Bugaud et al. (2001) analisando o efeito da dieta, verificaram que leite a partir de dietas em pastagens ricas em dicotiledôneas, em particular Apiaceae, contém grande quantidade de terpenos, que leite oriundos de pastagens ricas em Gramineae. No entanto, conteúdo de compostos voláteis, composição caseínica, Ca e P não são influenciados pelo tipo de pastagens. Já Beltrão Filho (2008), cita que o farelo de milho utilizado na formulação das rações experimentais foi determinante para a modificação da qualidade do leite de cabras, provocando a redução do teor de lipídios, de sólidos totais, de ácidos graxos monoinsaturados e a concentração de ácidos graxos desejáveis, incrementando, expressivamente, os ácidos graxos saturados.

$\mathrm{Na}$ Tabela 1 são reportados dois ensaios que envolveram modificações na dieta, em função do teor de concentrado. Costa et al. (2008) - Experimento 1, comparando a utilização de silagem de maniçoba misturada à ração nas proporções de 30:70, 40:60, 50:50 ou 60:40 volumoso:concentrado e Beltrão Filho (2008) - Experimento 2, avaliando dietas constituídos com diferentes níveis de palma forrageira $(0,25,50,75$ e $100 \%)$ em substituição ao farelo de milho. Portanto, a dieta oferecida aos caprinos pode alterar a composição e oflavourdo leite, e por isso é importante conhecer de que forma os diferentes tipos de alimentos promovem mudanças biológicas nos mecanismos de síntese de seus componentes e as suas consequiências em vários aspectos do leite.

\section{Uso de óleos em dietas de cabras leiteiras}

Os diferentes tipos de lipídios dependem dos diferentes ácidos graxos que as compõem. As razões para suplementar pequenos ruminantes com lipídios têm se tornado uma estratégia bastante estudada por diversos autores (Palmquist et al., 1993; Chilliard et al., 2003; Schmidely at al., 2005) que observaram a exploração desses animais em zonas áridas ou semi-áridas freqüentemente associados a alternância de escassez de comida.

Durante os períodos com disponibilidade de alimentos, os animais podem acumular reservas corpóreas que serão usadas no período de escassez de alimentos; neste

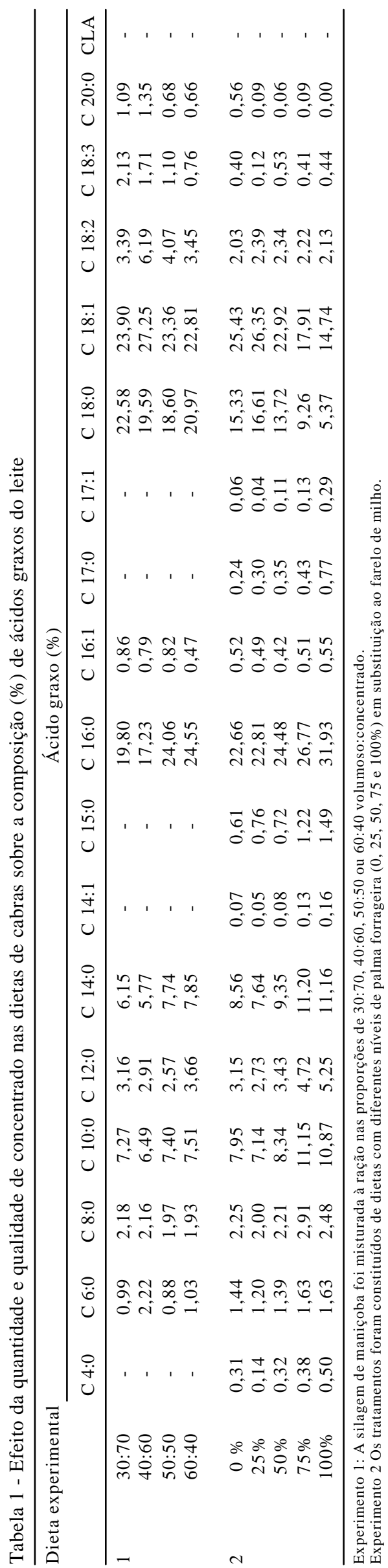

(c) 2009 Sociedade Brasileira de Zootecnia 
momento, os animais geralmente são confinados para manter os níveis de produção, utilizando-se concentrados na dieta, podendo ocasionar redução na produção de gordura no leite. Nessas circunstâncias, a substituição de parte do concentrado por lipídios pode trazer benefícios econômicos e melhorar o perfil de ácidos graxos do leite (Sanz Sampelayo et al., 2007).

A utilização de óleos na alimentação animal vem sendo realizada intensivamente no intuito de promover mudanças químicas, físicas e sensoriais, dentre outras. Outro interesse é na busca da produção de compostos alimentares benéficos à saúde humana, haja vista que o desenvolvimento de alimentos funcionais e produtos nutracêuticos têm sido cada vez mais estudados e direcionados aos consumidores que vêem se tornando claramente mais exigentes. No entanto, existe a possibilidade de efeitos negativos com a suplementação de gorduras nas dietas de ruminantes, pois pode levar a uma queda no consumo de alimentos, redução no conteúdo de proteína e danos na microbiota ruminal (Palmquist et al., 1993). Os ácidos graxos linoléico (C18:2) e linolênico (C18:3), os principais ácidos graxos dos vegetais, podem ser encontrados em quantidades muito pequenas na gordura corporal dos ruminantes e são tidos como essenciais, por não serem sintetizados pelos animais, devendo fazer parte da dieta dos mesmos. Estão presentes em abundância em óleos vegetais como os de girassol, canola, soja e linhaça, e sua concentração no leite e na carne de bovinos pode ser elevada se os animais forem alimentados com dietas ricasem óleo de cereais e sementes (Demeyer \& Doreau, 1999).

Os estudos utilizando fontes de gorduras na alimentação de ruminantes são necessários pelo interesse que despertam por parte dos pesquisadores em produzir alimentos diferenciados de origem animal e pela demanda do mercado consumidor em obter tais produtos. Essa melhoria foi observada por Sanz Sampelayo et al. (2002), que estudou o efeito da adição de 9 e $12 \%$ de gordura protegida rica em PUFAs e verificou diminuição na proporção total de ácidos graxos saturados. Os autores reportaram um aumento significante nas proporções de C14:1, C16:1, C18:2, C18:3, C20:2 e decréscimo de C18:0. Os resultados indicaram que a atividade ruminal não foi afetada pelo nível de adição de gordura, uma vez que não houve diminuição na proporção dos ácidos graxos até 14 átomos de carbono, que são provenientes da síntese de novo e, portanto, da concentração molar do acetato resultado da digestão das fibras no rúmen. Assim, presume-se que é possível, a partir da utilização de suplementos concentrados formulados com óleos que apresentem conteúdo elevado de ácido linoléico, obter teores elevado de ácidos graxos poliinsaturados, especialmente o CLA na gordura do leite caprino. Ressalta-se, também, a importância de estudos com raças nativas brasileiras e os possíveis efeitos da suplementação com forragens nativas, buscando-se, desta forma, a ascensão do potencial das regiões semi-áridas nordestina.

Os óleos vegetais contêm uma alta proporção de ácidos graxos insaturados, em relação aos saturados e uma digestibilidade aparente mais alta que as fontes lipídicas de origem animal. Conseqüentemente, os óleos vegetais são, comumente, mais benéficos nas dietas iniciais que as gorduras de origem

Os ácidos graxos linoléico (C18:2) e linolênico (C18:3), os principais ácidos graxos dos vegetais, podem ser encontrados em quantidades muito pequenas na gordura corporal dos ruminantes e são tidos como essenciais, por não serem sintetizados pelos animais, devendo fazer parte da dieta dos mesmos. Estão presentes em abundância em óleos vegetais como os de girassol, canola, soja e linhaça e sua concentração no leite e na carne de bovinos pode ser elevada se os animais forem alimentados com dietas ricas em óleo de cereais e sementes (Demeyer \& Doreau, 1999).

A produção de óleos vem crescendo a cada ano, principalmente em função da produção de biodiesel, fonte de combustível vegetal promissor no Brasil e no mundo. Em 2004, a produção de óleo do Brasil foi de $89 \%$ para o de soja, $2 \%$ para o de palma, $1 \%$ para o de mamona e $8 \%$ para os outros. Já entre 2005 e 2006, a Região Norte produziu 9\% da produção do país, sendo 141 milhões/litros/ano de óleo de soja e 140 milhões/litros/ano de óleo de palma, a Região Nordeste foi responsável por $14 \%$ da produção com 373 milhões/litros/ano de óleo de soja, 97 milhões/litros/ano de óleo de mamona e 87 milhões/litros/ano de óleo de algodão e a Região Centro-Sul produziu 77\%, sendo 5.197 milhões/ litros/ano de óleo de soja e 391 milhões/litros/ano de óleos como algodão, girassol, amendoim e outros (Abiove, 2006).

Os trabalhos utilizando fontes de gorduras na alimentação de animais, em especial de ruminantes, são necessários pelo interesse que despertam por parte dos pesquisadores em produzir alimentos diferenciados de origem animal e pela demanda do mercado consumidor em obter tais produtos. Desta maneira, a suplementação com lipídios para animais domésticos poderá se tornar corriqueira fazendo com que as indústrias produtoras de óleos tornemse cada vez mais eficaz. Além disso, possivelmente haverá a procura pelo desenvolvimento de um processamento que gere custos menores, destinando uma produção de óleos 
específicos para a alimentação animal, contribuindo assim, para a melhoria das características físico-químicas como o aumento de ácidos graxos insaturados, visando destacar as propriedades funcionais dos alimentos tornando-os cada vez mais valorizados pelos consumidores.

Resultados de três experimentos são listados na Tabela 2, os quais foram extraídos de ensaios envolvendo a adição de óleos nas dietas de cabras. Fernandes et al. (2008) - Experimento 1, Comparando a suplementação com óleos de diferentes fontes (algodão e girassol) e níveis na dieta (3 e 5\%); Pereira (2009) - Experimento 2, avaliando o efeito da adição de com óleos de distintas fontes (licuri e mamona) e níveis na dieta (3 e 5\%) e Bernard et al. (2009) - Experimento 3, avaliação do mecanismo de regulação da síntese ácidos graxos a partir de dietas com dietas baseadas em feno com e sem óleos de girassol ou linhaça (55 g/kg dieta MS).

\section{Metabolismo do lipídio no rúmen}

Naturalmente, os ácidos graxos linoléico e linolênico são fornecidos principalmente, pelos concentrados e forragens dietéticas, respectivamente. Quando os lipídios dietéticos entram no rúmen, a etapa inicial é a hidrólise das ligações ésteres dos triglicerídeos, dos fosfolipídios e dos glicolipídios. O glicerol liberado é utilizado para produção de ácidos graxos voláteis (AGVs), entretanto, as bactérias não são capazes de utilizar os ácidos graxos para produção de energia (Church, 1998).

A hidrólise dos lipídios dietéticos no rúmen envolve as lipases extracelulares que são produzidas por bactérias ruminais. A extensão da hidrólise dos lipídios dietéticos no rúmen é geralmente elevada, em torno de $50 \%$ para óleos de origem animal e de $85 \%$ para óleos vegetais (Doreau \& Ferlay, 1994). Há pouca evidência para relatar papéis significativos da hidrólise ruminal por protozoários e fungos do rúmen, ou por lipases da saliva ou de plantas (Bauman \& Lock, 2006).

A biohidrogenação dos ácidos graxos poliinsaturados é a segunda maior transformação que os lipídios dietéticos passam no rúmen e este processo requer primeiro que os ácidos graxos estejam livres. Contudo, a quantidade de ácidos graxos esterificados é sempre menor que a hidrólise realizada, afetando tanto a hidrólise quanto os níveis de biohidrogenação (Harfoot \& Hazlewood, 1997).

A etapa inicial da biohidrogenação ruminal dos ácidos linoléico e linolênico envolve um isomerização da dupla ligação cis-12 à configuraçãotrans-11, tendo por resultado um ácido graxo dienóico ou trienóico conjugado (Figura 1).



Figura 1 - Caminho da síntese ruminal endógena do ácido rumênico (C18:2 cis-9, trans-11 CLA) em vacas leiteiras. Os caminhos para a biohidrogenação dos ácidos linoléico e linolênico que chegam a ácido vacênico (C18:1 trans-11) são mostrados na síntese endógena do rúmen e pela ação da Ä9-desaturase são mostrados na glândula mamária. Adaptado de Bauman et al. (2003). 


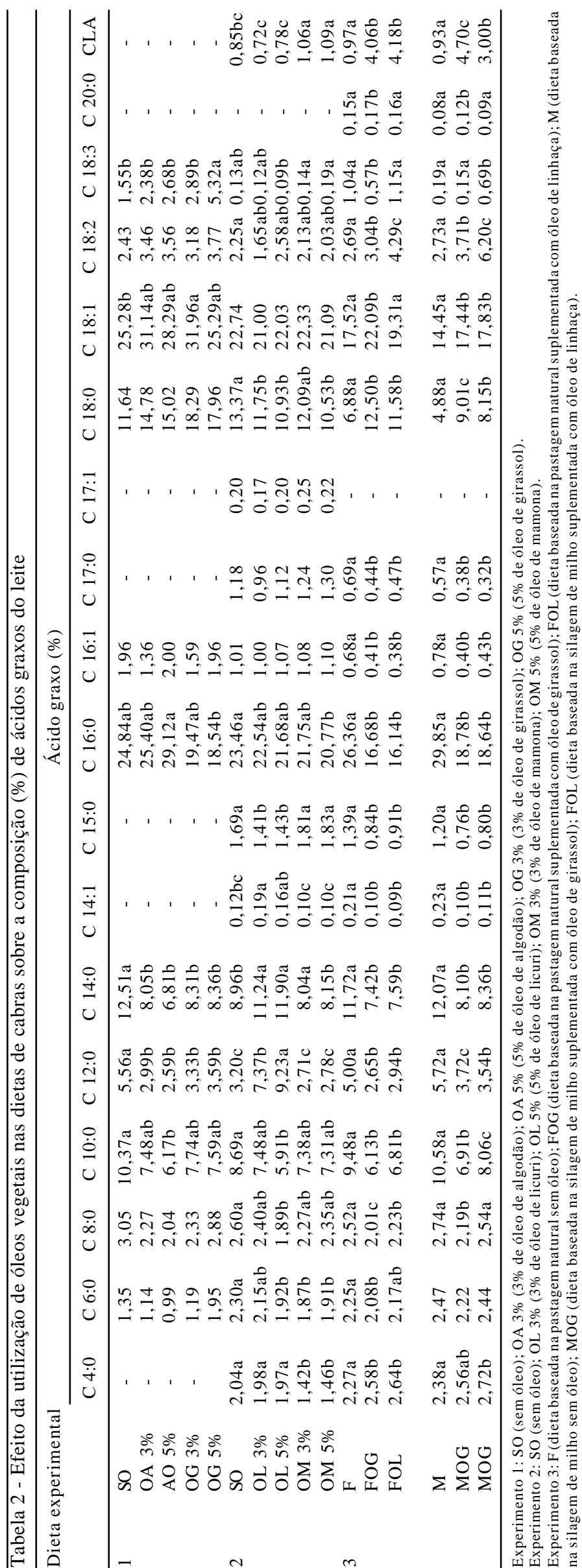

Em seguida, ocorre uma redução da dupla ligação cis-9 resultando no ácido vacênico (C18:1 trans-11). Conseqüentemente, o ácido rumênico é um intermediário formado somente durante a biohidrogenação do ácido linoléico (Bauman \& Lock, 2006). A conversão do ácido rumênico (C18:2 cis-9 trans-11) a ácido vacênico (C18:1 trans-11) é catalisada por uma redutase. Na Figura 1, o ácido vacênico é mostrado como um intermediário da biohidrogenação dos ácidos linoléico e linolênico.

A etapa final é dada por mais uma redução do ácido vacênico produzindo o ácido esteárico (C18:0). Essa redução é geralmente a etapa limitante, havendo assim, um freqüente acúmulo de ácidos graxos trans no rúmen (Kadzere \& Jingura, 1993).

Com o aprimoramento das técnicas analíticas podese avaliar complexidade dos processos da biohidrogenação que ocorrem no rúmen. Além dos principais caminhos que envolvem o ácido rumênico e ácido vacênico como intermediários, deve haver muitos caminhos adicionais. Uma grande quantidade de C18:1 trans e de isômeros do CLA são produzidos durante a biohidrogenação e, ainda não há explicação para esse processo (Bauman \& Lock, 2006).

A isomerase é a enzima que catalisa a etapa chave introduzindo o sistema da dupla ligação conjugada e, infelizmente, este enzima tem sido estudada somente em algumas espécies das bactérias ruminais. A isomerase produzida pela Butyrivibrio fibrisolvens é um enzima particularmente limitada à membrana bacteriana da célula $\mathrm{e}$ têm uma exigência absoluta para o sistema dienocis-9, cis12 e grupo carboxílico livre (Kepler et al., 1970). Se a isomerização inicial envolver a dupla ligação $c i s-12$, então uma dupla conjugadacis-9,trans-11 é produzida, caso seja a $c i s-9$, então a dupla conjugada trans-10, cis-12 é produzida. A maioria das bactérias do rúmen é capaz de realizar esta isomerização produzindo principalmente ácido vacênico do ácido linoléico. Entretanto, Kim et al. (2002), demonstraram que a bactéria do rúmen, a Megasphaera elsdenii YJ-4, produziu predominantemente, um isômero do CLA (C18:2 trans-10, cis-12) e apenas uma pequena quantidade de ácido rumênico, quando confrontada com o ácido linoléico.

Palmquist et al. (2005) revelaram que o tipo de dieta consumida pelos animais parece ser melhor que a quantidade oferecida, sendo o fator principal no processo da biohidrogenação, pois as mudanças na dieta produzidas por indução na alimentação podem alterar o caminho da biohidrogenação, tendo como resultado mudanças dramáticas nos ácidos graxos intermediários. Dieta com alto nível de concentrado diminui o $\mathrm{pH}$ ruminal, sendo também 
um fator que pode resultar na inibição de biohidrogenação dos PUFAs, provocando um acúmulo de trans C18:1 (Kalscheur et al., 1997).

Diante deste quadro, é possível supor que a manipulação alimentar é capaz de produzir intermediários do CLA mais facilmente que pelo conhecimento e manipulação das bactérias ruminais e suas enzimas.

Utilização de diferentes mecanismos para melhorar o perfil lipídico do leite

Os numerosos estudos mostraram que a dieta é o fator mais significante para afetar o conteúdo de CLA e outros ácidos graxos poliinsaturados da gordura de leite, e sua concentração pode ser diversas vezes aumentada por meios dietéticos (Chilliard et al., 2000; 2001; Lock \& Bauman, 2004). O teor de ácidos graxos encontrados na maioria das rações animais é relativamente baixo, enquanto varia de $18 \%$ a $40 \%$ em sementes de oleaginosas que podem ser usadas como suplementos (Berchielli et al., 2006).

Uma das chaves para elevação do conteúdo de CLA na gordura do leite é aumentar o consumo dietético de PUFAs com 18 carbonos, fornecendo desse modo mais substrato para a biohidrogenação. A suplementação dietética com os ácidos linoléico e linolênico é aumentada mais facilmente pela adição dos óleos vegetais ricos nestes ácidos graxos e, vários óleos vegetais tem sido investigados e mostrados como efetivos em aumentar o nível de CLA na gordura de leite. O ácido linoléico (C18:2) predomina na maior parte dos lipídios das sementes, enquanto que nas forragens, o acido linolênico (C18:3) encontra-se em maior concentração (Palmquist \& Jenkins, 1980). De acordo com Berchielli et al. (2006), algumas exceções importantes incluem o óleo de palma (alto teor de C16:0), óleo de canola (alto teor de C18:1 n-9) e o óleo de linhaça (alto teor de C18:3 n-3).

Apesar dos lipídios, normalmente somarem menos de $5 \%$ da dieta de rminantes, possuem um papel muito importante no metabolismo energético desses animais quando comparado aos não ruminantes. Isso pode ser comprovado quando a quantidade de ácidos graxos secretada no leite comumente excede sua ingestão (Palmquist \& Jenkins, 1980). A utilização de lipídios acima de $5 \%$ na alimentação de ruminantes está diretamente ligada a alterações nos padrões de fermentação ruminal. Os principais mecanismos envolvidos neste processo incluem o recobrimento físico da fibra, os efeitos tensoativos sobre as membranas microbianas e a diminuição na disponibilidade de cátions pela formação de sabões, que pode influenciar o $\mathrm{pH}$ ruminal, limitando o crescimento microbiano (Cenkvari et al., 2005).
A suplementação com lipídios insaturados apresenta efeitos desejáveis, como inibição da produção de metano, redução da concentração de amônia (NH3) ruminal, aumento na eficiência da síntese microbiana (Jenkins, 1993; Harfoot \& Hazlewood, 1997; Bateman \& Jenkins, 1998) e aumento na concentração de ácido linoléico conjugado (CLA) no leite. O metano tem relação direta com a eficiência de fermentação ruminal em virtude da perda de carbono ou hidrogênio e, conseqüentemente, perda de energia, determinando menor desempenho animal (Berchielli et al., 2006), portanto, minimizar a perda de metano é conveniente para o animal.

As respostas a suplementação lipídica são diferente de acordo com a espécie: para as cabras e ovelhas a secreção de gordura aumenta enquanto nas vacas pode aumentar ou ainda, haver diminuição (Chilliard et al., 2003). Essas diferenças podem estar ligadas ao complexo digestivo e a interações metabólicas (observada em vacas), a dieta basal (natureza e proporção entre volumoso:concentrado), a suplementação lipídica (natureza e quantidades) e as características do animal (espécie, raça, estágio de lactação) (Bauman \& Griinari, 2001). Para essas diferenças foi sugerido que a taxa de passagem é maior em cabras que em vacas, podendo diminuir em cabras o efeito ruminal sobre os lipídios e reduzir a lipogênese mamária em vacas (Chilliard et al., 2003).

A descoberta de benefícios do CLA à saúde e o reconhecimento do seu potencial como um componente funcional do alimento em leites e derivados estimulou a pesquisa para identificar fatores que afetam o índice de CLA da gordura de leite. Estes empenhos focalizaram em realçar o índice de CLA por unidade de gordura e centrou-se no ácido rumênico como o isômero predominante de CLA. As técnicas mais utilizadas pelos pesquisadores para obtenção de um perfil lipídico melhorado tem sido a utilização de ácidos graxos poliinsaturados (ácidos linoléico e linolênico) na forma de óleo vegetal, gorduras protegidas ou inertes (uso dos sabões de cálcio e lipídios protegidos quimicamente), disponibilidade de pasto fresco ou sementes de plantas oleaginosas.

Óleos vegetais

Uma escala de óleos vegetais que contêm os ácidos linoléico e linolênico, tem sido mostrado com eficiência em aumentar o índice de CLA da gordura de leite (Dhiman et al., 2000; Abughazaleh et al., 2001; Chouinard et al., 2001, Bernard, et al., 2009). Os óleos de sementes e óleos protegidos quimicamente oferecem algum benefício administrado em quantidades elevadas enquanto os efeitos 
negativos do metabolismo microbiano ruminal não começarem (Bauman et al., 2003).

Diversas situações dietéticas exercem efeitos de inibição e incluem alterações na relação volumoso:concentrado, suplementos dietéticos com óleos de peixe e a alimentação restringida (Bauman et al., 2000), sendo o uso do óleo de peixe o mais consistente, pois tem mostrado que fornece precursores muito pequenos de PUFAs com 18 carbonos que permitem a saída aumentada de ácido vacênico do rúmen, indicando que este aumento ocorre com uma inibição da biohidrogenação do mesmo (Bernard et al., 2009).

Óleos vegetais, ricos em ácidos graxos insaturados, podem acarretar efeitos negativos no ambiente ruminal, incluindo a diminuição da digestibilidade das frações fibrosas da dieta. Vargas et al. (2002), referem-se aos danos causados pela diminuição da degradação das fibras devido a sua grande reatividade a membrana celular das bactérias, podendo alterar a permeabilidade da membrana e reduzir a capacidade de regulação do $\mathrm{pH}$ intracelular e captação de nutrientes e também pela adsorção dos ácidos graxos à partículas dos alimentos que inibe o contato direto das células bacterianas ao substrato, reduzindo o crescimento microbiano, assim como a digestão de nutrientes. As bactérias gram-positivas são as que apresentam maior sensibilidade.

Bernard et al. (2009) em estudo avaliando o efeito de dietas com óleos vegetais concluíram que os óleos vegetais na dieta realçam a síntese da gordura de leite, alteram a composição de ácido graxo do leite e inibem especificamente a atividade mamária de estearoil-CoA desaturase na cabra. Além disso, o regulamento do lipogênese mamária em resposta aos óleos vegetais parece está relacionado aos fatores da expressão mamária alterada do gene ou do potencial da atividade de enzimática.

De mesma forma, Pereira (2009) observou efeito da adição de óleos nas dietas de cabras, verificando que a suplementação com o óleo de licuri ou mamona foi efetiva em promover as alterações no leite caprino com a influência no perfil de ácidos graxos em que, a inclusão do óleo de mamona elevou o teor de ácidos graxos poliinsaturados, benéficos à saúde humana. Por sua vez, o emprego do óleo de licuri causa variação negativa pelo incremento na concentração dos ácidos graxos saturados, ressaltando que esta característica pode ser relevante para a indústria de laticínios, devido à estabilidade que pode ser conferida ao leite.

Fernandes et al. (2008), também relataram influência na utilização de óleos de algodão ou girassol, observando que a adição de óleo na dieta diminuiu a quantidade de ácidos graxos de cadeia curta, como o mirístico, que pode proporcionar sérios problemas à saúde. Já o óleo de girassol a 5\% na MS aumentou a concentração de ácidos graxos poliinsaturados, principalmente o linolênico, que pode tornar o leite um produto melhor para o consumo humano, tendo em vista o provável efeito deste ácido graxo na prevenção de problemas cardiovasculares.

Essas respostas, no entanto, não devem ser generalizadas, pois estão intimamente relacionadas à forma de inclusão dos lipídios nas dietas, ao grau de instauração e ao comprimento da cadeia. Portanto, este processo tem relação direta com a composição nutricional da dieta ingerida pelo ruminante e as quantidades de óleo que são oferecidas.

\section{Gorduras protegidas ou inertes}

Para minimizar alguns efeitos negativos causados pelos óleos vegetais, como: a diminuição da digestibilidade das frações fibrosas da dieta e maior proporção de ácidos graxos saturados no abomaso e no intestino, diminuindo o aporte energético ao animal visto que são pouco digestíveis, tem-se sugerido o uso de gorduras inertes ao ambiente ruminal. O termo gordura inerte, refere-se a redução do efeito negativo que certos lipídios exercem sobre o metabolismo de protozoários e bactérias no rúmen (Smith, 1990).

Nos primeiros trabalhos com lipídios inertes, foi utilizada matriz protéica tratada com formaldeído (McAllan et al., 1983). O uso de gordura animal também foi proposto, como alternativa para aumentar a concentração energética das dietas, sem afetar a fermentação ruminal, apresentando, no entanto, maior grau de saturação, que implica menor absorção intestinal (Jenkins et al., 2008).

Os sabões de cálcio são degradados no rúmen em pequena proporção e, após hidrólise no abomaso, seus ácidos graxos podem ser absorvidos, reduzindo os efeitos negativos sobre a fermentação ruminal (Gonzalez et al., 1998). No entanto, as mesmas propriedades físicas que contribuem para a ausência de efeito das gorduras inertes sobre o metabolismo ruminal também podem refletir em uma redução na absorção intestinal de ácidos graxos (Smith, 1990).

Para se obter maior eficiência de proteção dos sais de cálcio de ácidos graxos insaturados é necessário manter um $\mathrm{pH}$ relativamente alto através da utilização de agentes alcalinizantes ou substâncias tamponantes, aumento da freqüência da alimentação ou fornecimento dos sais de cálcio após a alimentação (Van Nevel \& Demeyer, 1996), pois em situações de alto $\mathrm{pH}$ ruminal não ocorre a dissociação dos sais de cálcio de ácidos graxos insaturados, e, estes são 
então, parcialmente protegidos da biohidrogenação pela ausência de um grupo carboxila livre.

Os óleos de sementes que são ricos em PUFA's com 18-carbonos processados de forma que estejam acessíveis às bactérias ruminais incrementam o nível de CLA, mas ainda assim não são tão eficientes quanto os óleos puros no aumento do CLA na gordura do leite (Lock \& Bauman, 2004). Assim como os óleos das sementes, os óleos protegidos quimicamente podem ser benéficos durante o fornecimento em quantidades elevadas, até o momento em que o metabolismo animal apresentar os efeitos negativos.

De acordo com Silva et al. (2007), a suplementação com grãos de soja promoveu a redução na taxa de passagem de sólidos devido ao seu conteúdo médio de fibra (18\%), presente em grande parte na casca. Isso aumenta o tempo de permanência, reduzindo a digestibilidade e o valor energético da dieta, devendo, portanto levar em consideração essas características peculiares das sementes oleaginosas na forma integral.

\section{Pastagem verde}

Os tratamentos dietéticos mais eficientes para aumentar o índice de CLA da gordura de leite são aqueles que aumentem a fonte de PUFAs com 18 carbonos. Entre estas fontes, um dos mais estudado é o pasto fresco, que por meio de pesquisas indicam aumento de 2 a 3 vezes no índice de CLA da gordura de leite, especialmente em vacas leiteiras (Stanton et al., 1997; Kelly et al., 1998; Dhiman et al., 1999). A resposta diminui proporcionalmente à medida que o pasto passa a amadurecer. Assim sendo, os níveis de CLA são sazonais, visto que quando o pasto fresco é abundante os níveis elevam-se e diminui durante toda a estação de crescimento (Banni et al., 1996).

Estes resultados não podem ser explicados inteiramente pela composição do ácido graxo e pela fonte de PUFAs que o pasto fornece, conseqüentemente, deve haver fatores ou componentes adicionais no pasto que promovem a produção do ácido vacênico no rúmen, gerando uma diminuição nestes componentes enquanto o pasto amadurece (Lock \& Bauman, 2004). Também foram investigados diferentes sistemas de cultivo, com avaliação da quantidade e tipo de forragem que alimentou o animal. No geral, os sistemas de produção com maior proporção de forragem fresca na dieta proporcionam níveis mais elevados de CLA na gordura de leite (Sanz Sampelayo et al., 2007).

\section{Características sensoriais e compostos voláteis}

Os compostos voláteis do leite influenciam na sua aceitação, podendo ser considerado um fator determinante para o consumo, tendo em vista que são abundantes no leite fresco. Muitas substâncias formadoras do sabor que estão presentes no leite de ovelhas são, provavelmente, originadas por intensas mudanças nos compostos do alimento durante a digestão e no metabolismo intermediário provenientes de processos microbianos e enzimáticos (Addis et al., 2006), como consequência a suplementação da alimentação de ruminantes com lipídios pode alterar o sabor dos alimentos por interferir no processo de biohidrogenação ruminal, o qual possibilita mudanças ou modificações da fração volátil do leite (Delacroix-Buchet \& Lamberet, 2000).

Um dos aspectos mais interessantes do leite de pequenos ruminantes segundo Sanz Sampelayo et al. (2007), diz respeito à natureza de sua gordura, por que além de ser o seu principal nutriente, é responsável pela origem de odores agradáveis ou desagradáveis. O leite de ovelhas e cabras (15-18\%) possui uma quantidade significativa de ácidos graxos de cadeia curta composta de 6-10 átomos de carbono (Chilliard et al., 2003), os quais propiciam um perfeito aproveitamento do produto pelo organismo, auxiliando no controle dos níveis de triglicerídeos no organismo humano.

Para o leite fresco existem várias rotas bioquímicas e químicas para formação dos compostos voláteis. O sabor oxidado da gordura do leite é originado, primariamente, dos ácidos linoléico e linolênico, como também de outros ácidos graxos poliinsaturados. A hidrólise de triacilgliceróis, catalisada por lípases, libera ácidos graxos de cadeia curta, que são determinantes no sabor dos laticínios (Hammond, 1998). Outro aspecto notável relativo ao perfil dos voláteis é o seu conteúdo de ácidos graxos de cadeia ramificada com menos de 11 átomos de carbono. Chilliard et al. (2001) afirmaram que estes compostos são em grande parte, responsáveis pelas características organolépticas dos produtos obtidos a partir do leite de pequenos ruminantes.

Vários autores (Fischer \& Scott, 1997; FernandezGarcia et al., 2004; Addis et al., 2006; Eknaes \& Skeie, 2006; Vazquez-Landaverde \& Qian, 2007) reportaram a importância dos compostos voláteis no leite, relatando nas pesquisas as variações sofridas pelo leite de ruminantes através da relação do que foi consumido com o produzido e abordam a necessidade de mais estudos sobre a influência das dietas no sistema alimentar de ruminantes sobre a qualidade do leite e seus produtos. Os compostos responsáveis pelo aroma e sabor apresentam estruturas químicas diversas derivadas dos principais constituintes dos alimentos, sendo suas características 





específicas capazes de estimular os receptores dos reflexos do gosto e do odor, para produzir uma resposta sincronizada e integrada, denominada sabor ou flavour. O aroma, res ultado da interação de vários compostos voláteis, e o termo sabor se referem aos compostos químicos responsáveis ao estímulo ou à própria estimulação dos receptores biológicos. Os consumidores consideram o sabor como uma das principais propriedades sensoriais, sendo decisivas na seleção, aceitação e ingestão dos alimentos.

A composição botânica das forragens que são ingeridas pelos ruminantes apresenta-se como um dos fatores que variam a qualidade sensorial do leite. Recentemente, vários estudos têm sido realizados para analisar o efeito específico da natureza das forragens, seu modo de conservação e diversidade botânica nas características sensoriais do leite (Coulon \& Priolo, 2002).

A gordura do leite é um nutriente muito importante e contribui significativamente com a formação do flavour caprino, especialmente pela relação lipídios / lipólise. Vários autores sugerem que esta característica peculiar do leite caprino deve-se a presença de ácidos graxos de cadeia curta (capróico - C6:0, caprílico - C8:0, cáprico C10:0) com teores duas vezes maiores que no leite de vaca, tornando-os quimicamente e sensorialmente distintos. A atividade de lípases no leite resulta na liberação de ácidos graxos de cadeia curta especialmente de C6:0 a C10:0 e ácidos graxos ramificados (4-metiloctanóico e 4etiloctanóico) responsáveis pelo flavour característico (Delacroix-Buchet \& Lamberet, 2000).

Segundo Morand-Fehr et al. (2000), estudando as características do sabor do leite de cabra, verificaram que podem ser atribuídas à presença de lipídios, particularmente sob a forma dos ácidos graxos de cadeia curta (capróico C 6:0, caprílico - C 8:0 e cáprico - C 10:0) quase três vezes maiores que no leite de vaca e, quando rompida, ativa enzimas, liberando ácidos graxos voláteis e de odores desagradáveis.

O sabor denominado caprino, quando acentuado, constitui-se como um dos fatores de recusa. Entretanto, as substâncias responsáveis pelo sabor do leite caprino e seus prováveis precursores não são ainda bem conhecidos. Alguns estudos têm sido realizados, relacionando-as a fatores genéticos associados à sua composição química e formas de manuseio do produto, com a conseqüente produção do sabor característico (Delacroix-Buchet \& Lamberet, 2000).

Costa et al. (2008) verificaram que a utilização de silagem de maniçoba em dieta para cabras não confere mudanças sensoriais perceptíveis no leite. A inclusão de silagem de maniçoba na alimentação de cabras leiteiras em níveis de até $60 \%$ da dieta não altera a composição e as características sensoriais do leite. Já Queiroga et al. (2009), analisando a inclusão de diferentes tipos e níveis de óleos na dieta de cabras, concluíram que a adição de óleos vegetais, em particular óleo de algodão, eleva o conteúdo de gordura, bem como o sabor caprino no leite.

$\mathrm{Na}$ Tabela 3 estão mostrados 4 ensaios experimentais referentes aos resultados da composição química e características sensoriais, nos quais foram avaliados os efeitos de diferentes manejos alimentares em cabras. Fernandes et al. (2008) - Experimento 1, comparando a suplementação com óleos de diferentes fontes (algodão e girassol) e níveis na dieta (3 e 5\%); Pereira (2009) Experimento 2, avaliando o efeito da adição de com óleos de distintas fontes (licuri e mamona) e níveis na dieta ( 3 e 5\%); Costa et al. (2008) - Experimento 3, comparando a utilização de silagem de maniçoba misturada à ração nas proporções de 30:70, 40:60, 50:50 ou 60:40 volumoso:concentrado e Beltrão Filho (2008) - Experimento 4 , avaliação de dietas constituídos com diferentes níveis de palma forrageira $(0,25,50,75$ e $100 \%)$ em substituição ao farelo de milho.

O perfil dos voláteis do leite de cabras alimentadas com palma forrageira foi avaliado por Beltrão Filho (2008). Foram identificados 146 compostos voláteis, classificados como: 29 hidrocarbonetos, 7 alcanos cíclicos, 6 terpenóides, 13 aromáticos, 30 ésteres, 18 alcoóis, 14 ácidos carboxílicos, 10 aldeídos (6 saturados e 4 insaturados), 1 amida, 9 cetonas, 1 éter, 3 lactonas e 5 compostos sulfurados. Do total de compostos voláteis identificados no leite de cabra, $42 \%$ foram reportados pela primeira vez, que são: 14 hidrocarbonetos, 8 hidrocarbonetos insaturados, 5 alcanos cíclicos, 6 aromáticos, 7 ésteres, 8 alcoóis, 2 ácidos carboxílicos, 1 ácido carboxílico insaturado, 3 aldeídos insaturados, 3 cetonas e 5 sulfurados. Dentre os compostos identificados destacam-se o álcool 2-pentanol, 2-metil propanol, o 2metil butanol e o octadecanol, os aldeídos pentadecanal e heptadecanal, os ésteres tetradecanoato de metila, tetradecanoato de butila e hexadecanoato de butila, e os hidrocarbonetos 5-metil 1-hexeno e o 2,3-dimetil pentano. Os compostos voláteis que foram influenciados pela substituição do farelo de milho por palma forrageira foram: o álcool isobutanol, o aldeído 2-hexadecenal, os ésteresacetato de butila e octadecanoato de metila, os hidrocarbonetos 3-metil hexano, 4-metiloctano e o nonadecano, todos com redução linear e efeito significativo.

Pereira (2009), estudando a influencia da adição de 
óleos nas dietas de cabras no perfil aromático do leite, observou que os compostos voláteis de maior área percentual foram: 2,3-pentanedione, 2-heptanona, 2-metilhexano, butirato-de-isopropila, 3-metilbutanal e o 2-pentanol. Dentre os 87 compostos identificados alguns foram reportados previamente em leite de cabra, a exemplo de Queiroga et al. (2005), que identificaram 128 compostos, dos quais $26 \%$ também foram identificados no trabalho citado. Os voláteis identificados em leite de cabra de ambas as pesquisas foram: 1 hidrocarboneto aromático, 1 terpenóide, 4 aldeídos, 3 alcoóis, 3 cetonas, 3 ácidos carboxílicos, 4 ésteres, 1 lactona e 3 compostos sulfurados. Fernández-Garcia et al. (2004) também reportaram 14 compostos voláteis identificados no leite de cabra adicionados com óleos de licuri e mamona; os voláteis identificados foram: 1 hidrocarboneto alifático e 1 cíclico, 2 terpenóides, 1 aldeído, 2 álcoóis, 3 cetonas e 4 ésteres. O hexanoato de etila, que vem sendo referenciado na literatura como um dos responsáveis pelo odor característico do leite caprino (Jaubert et al. 1997), variou quando os animais foram alimentados com dietas adicionadas de $5 \%$ do óleo de licuri ou $5 \%$ de óleo de mamona. Os terpenóides foram influenciados pelos dois óleos, tendo sido mais alterado quando se adicionou $3 \%$ do óleo de licuri ou de mamona na dietas das cabras leiteiras. Segundo Mariaca et al. (1997) os compostos terpenóides ocorrem em maiores quantidades no leite e derivados quando os animais são alimentados com forragem fresca, especialmente, composta de dicotiledôneas, sendo a mamona classificada como tal.

\section{Considerações Finais}

A composição química e sensorial do leite é modificada pela redução da ingestão de lipídios pelos animais, provocando o incremento dos ácidos graxos saturados e depressão dos ácidos graxos insaturados, alterando o flavor do leite caprino com evidência do sabor rançoso.

É de relevância conhecer os nutrientes ou misturas alimentares que possuem fatores que possam interferir no processo fermentativo ruminal, devendo ser utilizados com cautela ou restrição, para não afetar o metabolismo do rúmen, o que proporciona efeito depreciativo ao organismo do animal. Da mesma forma, esta premissa aplica-se aos possíveis efeitos benéficos na qualidade do leite produzido.

O uso de técnicas biológicas moleculares poderá contribuir para o entendimento do mecanismo de utilização do alimento no rúmen e talvez estabeleça um novo cenário da microbiologia do rúmen, que pode ser diferente do que tem sido até hoje estudado.

\section{Literatura Citada}

ASSOCIAÇÃO BRASILEIRA DE INDÚSTRIAS DE ÓLEO VEGETAL - ABIOVE. In: SIMPÓSIO DE AGRONEGÓCIO DE PLANTAS OLEAGINOSAS: MATÉRIA-PRIMA PARA O BIODIESEL, 2., 2006, Piracicaba. Anais... Piracicaba: 2006.

ABUGHAZALEH, A.A.; SCHINGOETHE, D.J.; HIPPEN, A.R. Conjugated linoleic acid and other beneficial fatty acids in milk from cows fed soybean meal, fish meal, or both. Journal of Dairy Science, v.84, p.1845-1850, 2001.

ADARVE, G.L; MORALES, E.R; MANRIQUE, J.M. et al. Milk production and composition in Malagueña dairy goats. Effect of genotype for synthesis of alpha s1-casein on milk production and its interaction with dietary protein content. Journal of Dairy Research, v.76, n.2, p.137-43, 2009.

ADDIS, M.; PINNA, G.; MOLLE,G. et al. The inclusion of a daisy plant (Chrysanthemum coronarium) in dairy sheep diet: 2. Effect on the volatile fraction of milk and cheese. Livestock Science, v.101, p.68-80, 2006.

BANNI, S.; CARTA, G.; CONTINI, M.S. et al. Characterization of conjugated diene fatty acids in milk, dairy products and lamb tissues. Nutrition Biochemistry, v.7, p.150-155, 1996.

BATEMAN, H.G.; JENKINS, T.C. Influence of soybean oil in high fiber diets fed to nonlactating cows on ruminal unsaturated fatty acids and nutrient digestibility. Journal of Dairy Science, v.81, n.9, p.2451-2458, 1998.

BAUMAN, D.E.; CORL, B.A.; PETERSON, D.G. The biology of conjugated linoleic acid in ruminants. In: ADVANCES IN CONJUGATED LINOLEIC RESEARCH, 2., 2003, Champaign. Anais... Champaign: AOCS Press Champaign, 2003. p.146-173.

BAUMAN, D.E.; BARBANO, D.M.; DWYER, D.A. et al. Production of butter with enhanced conjugated linoleic acid for use in biomedical studies with animal models. Journal of Dairy Science, v.83, p.2422-2425, 2000.

BAUMAN, D.E.; GRIINARI, J.M. Regulation and nutritional manipulation of milk fat: low-fat milk syndrome. Livestock Production Science, v.70, p.15-29, 2001.

BAUMAN, D.E.; LOCK, A.L. Conjugated linoleic acid: biosynthesis and nutritional significance. In: FOX, P.F.; MCSWEENEY, P.L.H. (Eds.) Advanced dairy chemistry. 3.ed. New York: Springer, 2006. v.2, p.93-136.

Beltrão FILHO, E.M. Produção, composição química e sensorial do leite de cabras alimentadas com palma forrageira (Opuntia ficus-indical. Miller) em substituição ao milho. 2008. 85f. Tese (Programa de Doutorado Integrado em Zootecnia) - Universidade Federal da Paraíba, Areia, 2008.

BERCHIELLI, T.T.; PIRES, A.V.; OLIVEIRA, S.G. Nutrição de ruminantes. Jaboticabal: FUNEP, 2006. 583p.

BERNARD, L.; SHINGFIELD, K.J.; ROUEL, J. et al. Effect of plant oils in the diet on performance and milk fatty acid composition in goats fed diets based on grass hay or maize silage. British Journal of Nutrition, v. 101, p.213-224, 2009.

BUGAUD, C.; S. BUCHIN, J.B.; COULON, A. et al. Influence of the nature of alpine pastures on plasmin activity, fatty acid and volatile compound composition of milk. Lait, v.81, p.401414, 2001.

BRASIL, L.H.A.; WECHESLER, F.S.; BACCARI JR., F. et al. Efeitos do estresse térmico sobre a produção, composição química do leite e respostas termorreguladoras de cabras da raça Alpina. Revista Brasileira de Zootecnia, v.29, n.6, p.1632-1641, 2000.

BRITO, C.O.; QUEIROGA, R.C.R.E.; COSTA, R.G. et al. Efeito do período de lactação na produção de leite de cabras Murciana Granadina. Revista do Instituto de Laticínios Cândido Tostes, v.59, 2004. 
CARVALHO, S.; RODRIGUES, M.T.; BRANCO, R.H. et al. Comportamento ingestivo de cabras alpina em lactação submetidas a dietas com diferentes níveis de fibra em detergente neutro. In: REUNIÃO ANUAL DA SOCIEDADE BRASILEIRA DE ZOOTECNIA, 38., 2001, Piracicaba. Anais... Piracicaba: Sociedade Brasileira de Zootecnia, 2001. (CD-ROM).

CENKVARI, E.; FEKETE, S.; FEBLE, H. et al. Investigation on the effects of Ca-soaps of oil linseed on rumen fermentation in sheep on milk composition of goats. Journal of Animal Physiology and Animal Nutrition, v.89, p.172-178, 2005.

CHILLIARD, Y.; FERLAY, A.; DOREAU, M. Effect of different types of forages, animal fat or marine oils in cow's diet on milk fat secretion and composition, especially conjugated linoleic acid (CLA) and polyunsaturated fatty acids. Livestock Production Science, v.70, p.31-48, 2001.

CHILLIARD, Y.; FERLAY, A.; MANSBRIDGE, R.M. et al. Ruminant milk fat plasticity: nutritional control of saturated, polyunsaturated, trans and conjugated fatty acids. Annales de Zootechnie, v.49, p.181-205, 2000.

CHILLIARD,Y.; FERLAY, A.; ROUEL, J. et al. A review of nutritional and physiological factors affecting goat milk lipid synthesis and lipolysis. Journal of Dairy Science, v.86, p.1751-1770, 2003.

CHOUINARD, P.Y.; CORNEAU, L.; BUTLER, W.R. et al. Effect of dietary lipid source on conjugated linoleic acid concentrations in milk fat. Journal of Dairy Science, v.84, p.680-690, 2001.

CHURCH, D.C. El rumiante: fisiologia digestiva y nutrición. Zaragoza: Acribia, 1998. 630p.

COULON, J.B.; HURTAUD, C.; REMOND, B. et al. Facteurs de variation de la proportion de caseínaes dans les proteins du lait de vache. INRA Produtions Animales, v.11, p.229-310, 1998.

COULON, J.B.; PRIOLO, A. La qualité sensorielle des produits laitiers et de la viande dépend des fourrages consommés par les animaux. INRA Productions Animales, v.15, n.5, p.333-342, 2002.

COSTA, R.G.; MESQUITA, I.V.; QUEIROGA, R.C.R. Características químicas e sensoriais do leite de cabras Moxotó alimentadas com silagem de maniçoba. Revista Brasileira de Zootecnia, v.37, n.4, p.694-702, 2008.

DELACROIX-BUCHET, A.; LAMBERET, G. Sensorial properties and typicity of goat dairy products. Tours/France: International Association of Goat, 2000. p.559-563.

DEMEYER, D.; DOREAU, M. Targets and procedures for altering ruminant meat and lipids. Proceedings of the nutrition society, v.58, p.593-607, 1999.

DHIMAN, T.R.; ANAND, G.R.; SATTER, L.D. et al. Conjugated linoleic acid content of milk from cows fed different diets. Journal of Dairy Science, v.82, p.2146-2156, 1999.

DHIMAN, T.R.; SATTER, L.D.; PARIZA, M.W. et al. Conjugated linoleic acid (CLA) content of milk from cows overed diets rich in linoleic and linolenic acid. Journal of Dairy Science, v.83, p.1016-1027, 2000.

DOREAU, M.; FERLAY, A. Digestion and utilization of fatty acids by ruminants. Animal Feed Science and Technology, v.45, p. 379-396, 1994

DUBEUF, J.P.; MORAND-FEHR, P.; RUBINO, R. Situation, changes and future of goat industry around the world.Small Ruminant Research, v.51, n.1, p.165-173, 2004.

EKNAES, M.; SKEIE, S. Effect of different level of roughage availability and contrast levels of concentrate supplementation on flavour of goat Milk. Small Ruminant Research, v.66, p.32-43, 2006.

FERNANDES, M.F.; QUEIROGA, R.C.R.E.; MEDEIROS, A.M. et al. Physico-chemical characteristics and fatty acid profile of milk of crossbred Moxotó goats supplemented with cottonseed or sunflower oil. Brazilian Journal of Animal Science, v.37, n.4, p.703-710, 2008

FERNÁNDEZ-GARCÍA, E.; CARBONEL, M.; GAYA, P.; NUÑEZ, M. Evolution of the volatile compounds of ewes raw milk
Zamorano cheese. Seasonal variation. International Dairy Journal, v.14, p.701-711, 2004

FERREIRA, M.C.C; QUEIROGA, R.C.R.E. Composição química do leite de cabras puras no Curimataú paraibano durante o período de lactação. Revista do Instituto de Laticínios Candido Tostes, v.58, n.330, p. 21-26, 2003.

FISHER, C.; SCOTT, T.R. Flavores de los alimentos - Biologia e química. Zaragoza: Acribia, 1997. 212p.

GOETSCH, A.L.; DETWEILER, G.; SAHLU, T. et al. Dairy goat performance with different dietary concentrate levels in late lactation. Small Ruminant Research, v.41, p.117-125, 2001.

GONZALEZ, M.F.; BAS, M.F.; LUQUE, L.V. Effect of the supplementation of hydrogenated fat (GHP) and a calcium salt of fatty acids, derived from fish oil, on in vitro digestibility of cell wall and volatile fatty acids production. Nutrition Abstract Reviews, v.69, p.797, 1998.

HAENLEIN, G.F.W. Goat milk in human nutrition. Small Ruminant Research, v.51, n.1, p.155-163, 2004.

HAMMOND, E.G. Flavor chemistry if lipid foods. London: Blackie Academic Professional, 1998. 237p.

HARFOOT, C.G.; HAZLEWOOD, G.P. Lipid metabolism in the rumen. In: THE RUMEN MICROBIAL ECOSYSTEM, 2., 1997, London. Proceedings... London: Chapman and Hall, 1997. p.382-426.

HOOVER, W.H.; STOKES, S.R. Balancing carbohydrates and proteins for optimum rumen microbial yield. Journal of Dairy Science. v.74, n.10, p.3630-3644, 1991.

JAUBERT, G.; BODINI, J.; JAUBERT, A. Biochemical characteristics and quality of goat milk. In:MORAND-FEHR, P. (Ed.) Recent advances in goats research. Zaragoza: CIHEAM-IAMZ, 1997. 93p.

JENKINS, T.C.; WALLACE, R.J.; MOATE, P.J. et al. Recent advances in biohydrogenation of unsaturated fatty acids within the rumen microbial ecosystem. Journal of Animal Science, n.86, p.397-412, 2008.

JENKINS, T.C. Symposium: advances in ruminant lipid metabolism - Lipid metabolism in the rumen. Journal of Dairy Science, v.76, p.3851-3863, 1993.

KADZERE, C.T.; JINGURA, R. Digestibility and nitrogen balance in goats given different levels of crushed whole soybeans. Small Ruminant Research, v.10, p.175-180, 1993.

KALSCHEUR, K.F.; TETER, B.B.; PIPEROVA, L.S. et al. Effect of dietary concentration and buffer addition on duodenal flow of trans-C18:1 fatty acids and milk fat production in dairy cows. Journal of Dairy Science, v.80, p.2104-2114, 1997.

KELLY, M.L.; KOLVER, E.S.; BAUMAN, D.E. et al. Effect of intake of pasture on concentrations of conjugated linoleic acid in milk of lactating cows. Journal of Dairy Science, v.81, p.1630-1636, 1998.

KEPLER, C.R.; TUCKER, W.P.; TOVE, S.B. Biohydrogenation of unsaturated fatty acids; IV: Substrate specity and inhibition of linoleate 12-cis, 11-trans-isomerase from Butyrivibrio fibrissolvens. Journal of Biological Chemistry, v.245, p.3612-3620, 1970.

KIM, Y.J.; LIU, R.H.; RYCHLIK, J.L. et al. The enrichment of a ruminal bacterium (Megasphaera elsdenii $\mathrm{YJ}-4$ ) that produces the trans-10, cis-12 isomer of conjugated linoleic acid. Journal of Applied Microbiology, v.92, p.976-982, 2002.

LE DOUX, M.; ROUZEAU, A.; BAS, P. et al. Occurrence of transC18:1 fatty acid isomers in goat milk: effect of dietary regimens. Journal of Dairy Science, v.85, p.190-197, 2002.

LOCK, A.L.; BAUMAN, D.E. Modifying milk fat composition of dairy cows to enhance fatty acids beneficial to human health. Lipids, v.39, p.1197-1206, 2004.

LUCAS, A.; ROCK'S, C.; AGABRIEL, L. et al. Relationships between animal species (cow versus goat) and some nutritional. Small Ruminant Research, v.74, n.1, p.243-248, 2008.

MARIACA, R.; BERGER, T.; GAUCH, R. et al. Occurrence of volatile mono and sesquiterpenoids in highland and lowland 
plant species as possible precursors for flavor compounds in milk and dairy products. Journal of Agricultural and Food Chemistry, v.45, n.11, p.4423-4434, 1997.

McALLAN, A.B.; KNIGHT, R.; SUTTON, J.D. The effect of free and protected oils on the digestion of dietary carbohydrates between the mouth and duodenum of sheep. British Journal of Nutrition, v.49, p.433-440, 1983.

MORAND-FEHR, P.; SANZ SAMPELAYO, M.R.; FEDELE, Y.V.; et al. Effets de l'alimentation sur la qualité du lait et des fromages de chèvres. In: INTERNATIONAL CONFERENCE ON GOATS, 7., 2000, France. Proceedings... France: IGA, 2000.

NOCEK, J.E. Bovine acidosis: implications on lameness. Journal of Dairy Science, v.80, n.5, p.1005-1028, 1997.

PALMQUIST, D.L.; BEAULIEU, A.D.; BARBANO, D.M. Feed and animal factors influencing milk fat composition. Journal of Dairy Science, v.76, p.1753-1771, 1993.

PALMQUIST, D.L.; LOCK, A.L.; SHINGWELD, K.J. et al. Biosynthesis of conjugated linoleic acid in ruminants and humans. In: ADVANCES IN FOOD AND NUTRITION RESEARCH, 50., 2005, San Diego. Proceedings... San Diego: Elsevier Inc., San Diego, 2005. p.179-187.

PALMQUIST, D.L.; JENKINS, T.C. Fat in lactation ration: review. Journal of Dairy Science, v.63, n.1, p.1-14, 1980.

PEREIRA, R.A.G. Impacto de dietas contendo óleo de licuri ou mamona nas características físico-químicas, sensoriais e aromáticas do leite de cabra. 2009. $111 \mathrm{f}$. Tese (Programa de Doutorado Integrado em Zootecnia) Universidade Federal da Paraíba, Areia, 2009.

PRASAD, H.; TEWARI, H.A.; SENGAR, O.P.S. Milk yield and composition of the beetal breed and their crosses with Jamunapari, Barbari and Black Bengal breeds of goat. Small Ruminant Research, v.58, p.195-199, 2005.

QUEIROGA, R.C.R.E.; MADRUGA, M.S.; GALVÃO, M.S. et al. Otimização das condições de extração de compostos voláteis em leite caprino utilizando a técnica de extração e concentração simultânea. Revista do Instituto Adolfo Lutz, v.64, n.1, p.97$103,2005$.

QUEIROGA, R.C.R.E.; COSTA, R.G.; BISCONTINI, T.M.B. et al. Influência do manejo do rebanho, das condições higiênicas da ordenha e da fase de lactação na composição química do leite de cabras Saanen. Revista Brasileira de Zootecnia, v.36, p.14, 2007.

QUEIROGA, R.C.R.E.; FERNANDES, M.F.; MEDEIROS, A.N. et al. Physicochemical and sensory effects of cotton seed and sunflower oil supplementation on Moxotó goat milk. Small Ruminant Research, v.82, n.1, p.58-61, 2009.
RAYNAL-LJUTOVAC, K.; LAGRIFFOUL, G.; PACCARD, P. et al. Composition of goat and sheep milk products: An update. Small Ruminant Research, v.79, p.57-72, 2008.

SANZ SAMPELAYO, M.R.; CHILLIARD, Y.; SCHMIDELY, P.H. et al. Influence of type of diet on the fat constituents of goat and sheep milk. Small Ruminant Research, v.68, p.42-63, 2007.

SANZ SAMPELAYO, M.R.S.; PÉREZ, L.; ALONSO, M.J.J. et al. Effects of concentrates with different contents of protected fat rich PUFAs on the performance lactating Granadina goats. Part II. Milk production and composition. Small Ruminant Research, v.43, p.141-148, 2002 .

SCHMIDELY, P.; MORAND-FEHR, P.; SAUVANT, D. Influence of extruded soybeans with or without bicarbonate on milk performance and fatty acid composition of goat milk. Journal of Dairy Science, v.88, p.757-765, 2005.

SILVA, M.M.C.; RODRIGUES, M.T.; BRANCO, R.H. et al. Suplementação de lipídios em dietas para cabras em lactação: consumo e eficiência de utilização de nutrientes. Revista Brasileira de Zootecnia, v.36, n.1, p.257-267, 2007.

SMITH, W.A. Fats for lactations dairy cows. In: CONGRESS OF THE SOUTH AFRICA SOCIETY AND ANIMAL PRODUCTION, 29., 1990, Stellenbosch. Proceedings... Stellenbosch: Animal production, University of Stellenbosch, 1990. p.1-10.

STANTON, C.; LAWLESS, F.; KJELLMER, G. et al. Dietary influences on bovine milk cis-9, trans-11-conjugated linoleic acid content. Journal of Food Science, v.62, p.1083-1086, 1997.

TORII, M.S.; SHIZUO; M.; DAMASCENO, J.C. et al. Physicalchemical characteristics and fatty acids composition in dairy goat milk in response to roughage diet. Brazilian Archives Biologic Technologic, v.47, n.6, p.903-909, 2004.

Van NEVEL, C.J.; DEMEYER, D.I. Influence of pH on lipolysis and biohydrogenation of soybean oil by rumen contents in vitro. Reproduction, Nutrition, Development, v.36, p.53-63, 1996.

VARGAS, L.H.; LANA, R.P.; JHAM, G.N. et al. Adição de lipídios na ração de vacas leiteiras: parâmetros fermentativos ruminais, produção e composição do leite. Revista Brasileira de Zootecnia, v.31, n.1, p.522-529, 2002.

VAZQUEZ-LANDAVERDE, P.A.; QIAN, M.C. Antioxidant impacts on volatile formation in high-pressure-processed milk. Journal of Agricultural and Food Chemistry, v.55, p.9183-9188, 2007. 